\title{
Equivalent Diameter of Standard Quartz Dust Used as a Test Aerosol for the Dust Respirator
}

\author{
Toshihiko MYOJO and Mitsumasa SUGIMOTO
}

National Institute of Industrial Health

Nagao, 6-21-1, Tama-ku, Kawasaki, 214 Japan

(Received February 8, 1996 and in revised form April 23, 1996)

\begin{abstract}
In the standard of the approval test for dust respirator certification, test aerosols are defined as air containing quartz particles of $2 \mu \mathrm{m}$ or smaller ${ }^{1)}$. However, it is well-known that the filtration efficiency of air filters depends on the size of the test aerosol particles. Alternative test aerosols containing submicron size particles will be studied for use in future approval test of dust respirators. Before searching for alternatives, characterization of currently-used quartz dust, e.g. information about size and electrostatic charge of the aerosol particles, should be determined.

The currently-used approval test measures filtration efficiencies with a light scattering photometer. The photometer gives overall aerosol concentration, while Aerodynamic Particle Sizer (APS-33B, TSI Inc., St. Paul, U.S.A.) is able to give the number concentration for each particle size based on the aerodynamic diameter ranging from 0.9 to $2.0 \mu \mathrm{m}$. In this study, equivalent diameter was defined as the diameter at which penetration has the same value when measured by APS-33B and by light scattering photometer. The equivalent diameter for the ten filter samples for dust respirator was around $1 \mu \mathrm{m}$, irrespective of neutralization of the test aerosol.
\end{abstract}

Key words: Test aerosol - Dust respirator - Certification - Quartz dust

\section{INTRODUCTION}

According to the current certification program for dust respirators ${ }^{1)}$, the performance of the filter has been evaluated using quartz dust. Until 1962, it had been tested by using limestone dust and filter performance was evaluated based on mass. More than three decades ago, a research and development project of National Institute of Industrial Health provided a high performance dust filter composed of wool felt coated with p-tert-butylphenol resin ${ }^{2,3)}$. Accompanying the development of this filter, the evaluation method of filtration efficiency was changed to the lightscattering method using photometers. This evaluation method using light-scattering photometers and quartz dust was authorized as an item of the test standard for dust respirators in Japan. 
The standards of dust respirators only specifies that the size of quartz particles must be less than $2 \mu \mathrm{m}$ in diameter. Consequently, even broad size distributions are allowable as the test aerosol particles as far as they satisfy the requirement. The results of the present performance test on filtration efficiency were reproducible. However, it is well-known that the filtration efficiency of air filter depends on the size of test aerosol particles. Furthermore, the light scattering photometer used to measure aerosol concentration is not size selective but its sensitivity depends on the size of test aerosol particles ${ }^{4,5}$. The current test method mentioned above may exhibit poor filtration efficiencies for aerosols containing submicron size particles.

Johnston et al. $\left.{ }^{6}\right)$ measured the electrostatic charge distribution of quartz and other mineral dusts dispersed by four mechanical dispersers. The quartz particles were found to be predominantly negatively charged. The charge levels on quartz dust can not be disregarded when aerosols are used as standard test aerosols for the dust respirators. Further, quartz dust is well-known to be a toxic substance causing silicosis. We need to search alternative test aerosols that can be used for approval test of dust respirators.

Sodium chloride aerosol is already used in other performance tests of the respiratory protective equipment ${ }^{7-10)}$, such as leakage rate test for facepieces of respirators $^{7)}$ and dust respirators for fine particles ${ }^{8)}$ according to the Japanese Industrial Standard (JIS). This aerosol can be used as an alternative to quartz dust as a test aerosol. However, replacement of test particles may change the measured filtration efficiency, because the sodium chloride aerosol contains submicron size particles defined that more than $90 \%$ of aerosol particles must be smaller than 0.5 $\mu \mathrm{m}$ in diameter.

The aim of this study is to determine the dominant size of quartz particles of the test aerosol used in the certification of dust respirators. In order to measure the filtration efficiency for each size range of test aerosol, an aerodynamic particle sizer (APS-33B, TSI Inc., St. Paul, U.S.A.) was combined with the instruments used for the standard performance test. Equivalent diameters of test aerosol particles used in the standard test were determined from the filtration efficiencies obtained by both APS-33B and standard light-scattering-photometers installed in the test system.

\section{EXPERIMENTAL APPARATUS AND PROCEDURE}

Figure 1 shows the system to measure the filtration efficiency of the dust respirators. During the collection efficiency test for dust respirators, the dust concentrations should be measured with photometers detecting the scattered light by aerosols. The instrument (AP634, Shibata Scientific Technology Ltd., Tokyo) used in this study was formerly used for national approval test at National Insti- 
tute of Industrial Health. It is composed of a box to set up a test filter, two detectors of light scattering photometers upstream and downstream the sample, the electric power supply for the detectors, and a indicator for dust concentration. Before measurement of the filtration efficiency, the instrument was adjusted by ordinary checkup procedures for standard scattering intensity and photomultiplier dark current.

For the filtration efficiency test, two sampling probes for APS-33B were inserted upstream and downstream the instrument and were switched by two ball valves driven by air actuators. The sampling time period was two and a half minutes for each side. The inner diameter of the sampling lines and ball valves was 10 $\mathrm{mm}$. In order to reduce inlet aerosol concentration to a range measurable by APS33B, 1/100 diluter (TSI Inc. Diluter 3302) was added upstream APS-33B.

Aerodynamic Particle Sizer (APS-33B) measures aerodynamic diameter based on the flight time of the particle in the acceleration nozzle ${ }^{11)}$. In the accelerating flow field, larger particles fly slower than smaller particles due to inertia. Particles ranging from 0.5 to $30 \mu \mathrm{m}$ can be detected by this instrument.

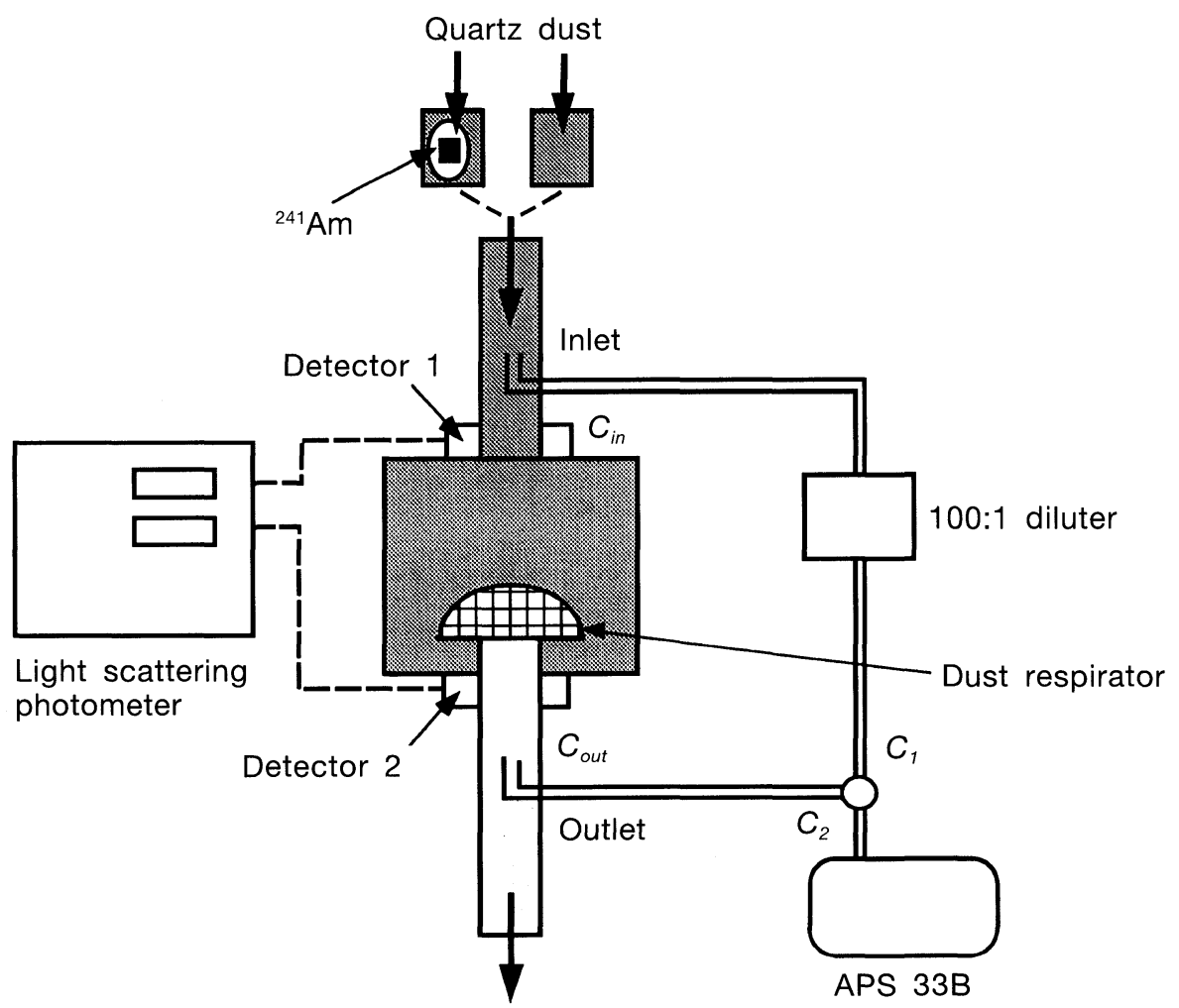

Fig. 1. Experimental apparatus to evaluate the filtration efficiency of air filters. 
Chen and Willeke ${ }^{12)}$ and Chen et al. ${ }^{13)}$ have already examined the particle-size dependence of aerosol penetration through filtering facepieces and cartridge-type dust respirators. By measuring the penetration of corn oil aerosols from 1 to 4 $\mu \mathrm{m}$ with APS-33B, and from 0.1 to $1 \mu \mathrm{m}$ with a laser aerosol spectrometer (LAS$X$ PMS Inc., Boulder, USA), they showed consistent data from these instrument.

Quartz powder is fed by an ejector type dust feeder (DF-5, Shibata Scientific Technology LTD., Tokyo), and then blown into a plenum chamber whose the volume was $27 \mathrm{~m}^{3}$. The quartz particles passed through the horizontal elutriator which removed particles of $2 \mu \mathrm{m}$ or more, and then were introduced into the test section shown in Figure 1. The inlet concentration of the test aerosol was kept about $5 \mathrm{mg} / \mathrm{m}^{3}$ which was lower than the standard concentration of $30 \mathrm{mg} / \mathrm{m}^{3}$ for the national approval test because $5 \mathrm{mg} / \mathrm{m}^{3}$ is the minimum controllable concentration of the present generation system, and it is nearly the maximum measurable concentration for APS-33B without coincidence error. For some cases, radioisotope ${ }^{241} \mathrm{Am}$ (3.7 $\mathrm{MBq}$; $\alpha$ ray source) was added upstream the test section to neutralize the electrostatic charges on dust particles.

Because this system can not control humidity, we have avoided days with extremely low or high humidity to generate the aerosol. The humidity in this study ranged from 30 to $60 \% \mathrm{RH}$.

In this study, six types of reusable filters and four types of filtering facepieces were used as test pieces. The filtration efficiencies of the eight pieces were measured for each type of filter. We define the equivalent diameter as the aerodynamic diameter of which penetration measured by APS-33B is the same as that measured by the photometers used for the approval test. If monodisperse quartz dust of equivalent diameters can be obtained as the test aerosol, both APS-33B and the photometers should indicate the same filtration efficiency for a test filter.

\section{Results AND Discussion}

Before the filtration performance test, a filter holder was connected to the sampling line for APS-33B and the quartz particles of the test aerosol were collected on a Nuclepore filter to ascertain particle size. Figure 2 shows a scanning electron micrograph of the collected quartz dust. Particles prepared by any milling process are commonly irregular in shape. The aerodynamic diameter of a particle measured by APS-33B is defined as the diameter of a unit-density sphere that has the same settling velocity as the particle in question. In industrial hygiene, the aerodynamic diameter is widely considered the most important size parameter because it is closely related to the deposition of dust and mist in the respiratory tract. As these irregularly-shaped particles have void and absorbed water, actual density of such quartz particles, as shown in Figure 2 is difficult to determine.

The penetration $\mathrm{P}(\%)$ and filtration efficiency $\mathrm{F}(\%)$ can be defined as below. 


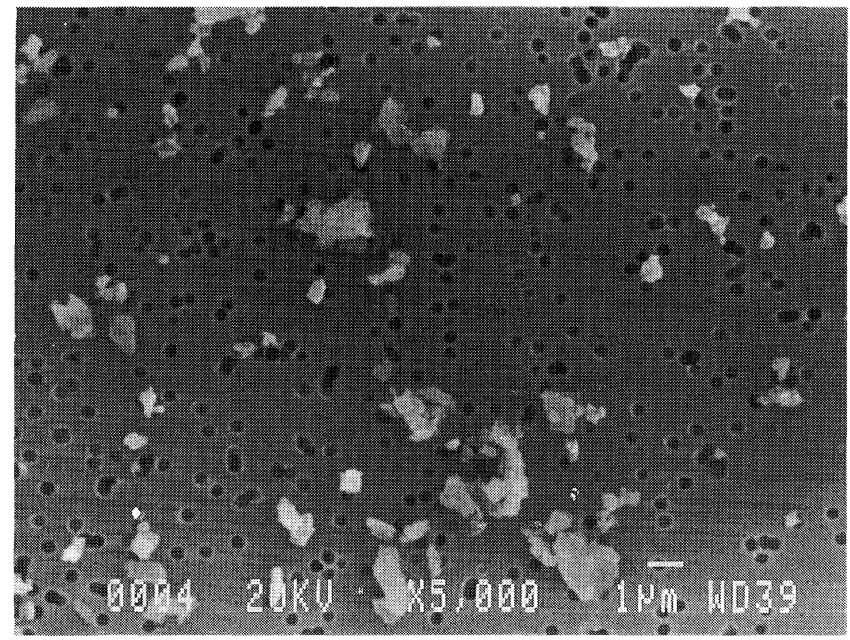

Fig. 2. Scanning electron micrograph of quartz particles collected on Nuclepore filter.

$$
\begin{aligned}
P & =100-F \\
& =\left(C_{\text {out }} / C_{\text {in }}\right) \times 100
\end{aligned}
$$

where $\mathrm{C}_{\text {in }}$ and $\mathrm{C}_{\text {out }}$ are the concentrations upstream and downstream the test filter. However, as we used a dilutor for upstream sampling line, Equation (1) is changed as below.

$$
P=\left(C_{2} / C_{1} \cdot D L\right) \times 100
$$

$\mathrm{C}_{1}$ and $\mathrm{C}_{2}$ are the concentrations measured by APS-33B from upstream line and downstream line as shown in Figure 1. DL is dilution factor. $\mathrm{P}=100 \%$, it corresponds to without any filter, is substituted for Equation (1).

$$
\mathrm{DL}=\mathrm{C}_{2} / \mathrm{C}_{1}
$$

Figure 3 shows the relationship between aerodynamic diameter and dilution factor DL as defined in Equation (3). Our preliminary experiments revealed that the average dilution factor DL is 94.5 in this system. Although APS-33B can detect particles greater than $0.5 \mu \mathrm{m}$ in diameter, DL changed sharply for quartz particles with diameters smaller than $0.9 \mu \mathrm{m}$. APS-33B might not count all of these small particles. The results of APS-33B in this system were valid for dust particles ranging from 0.9 to $2.0 \mu \mathrm{m}$.

Figure 4 shows the relationship between aerodynamic diameter and penetration $P$ through the test filters using quartz dust with and without neutralizer. The 


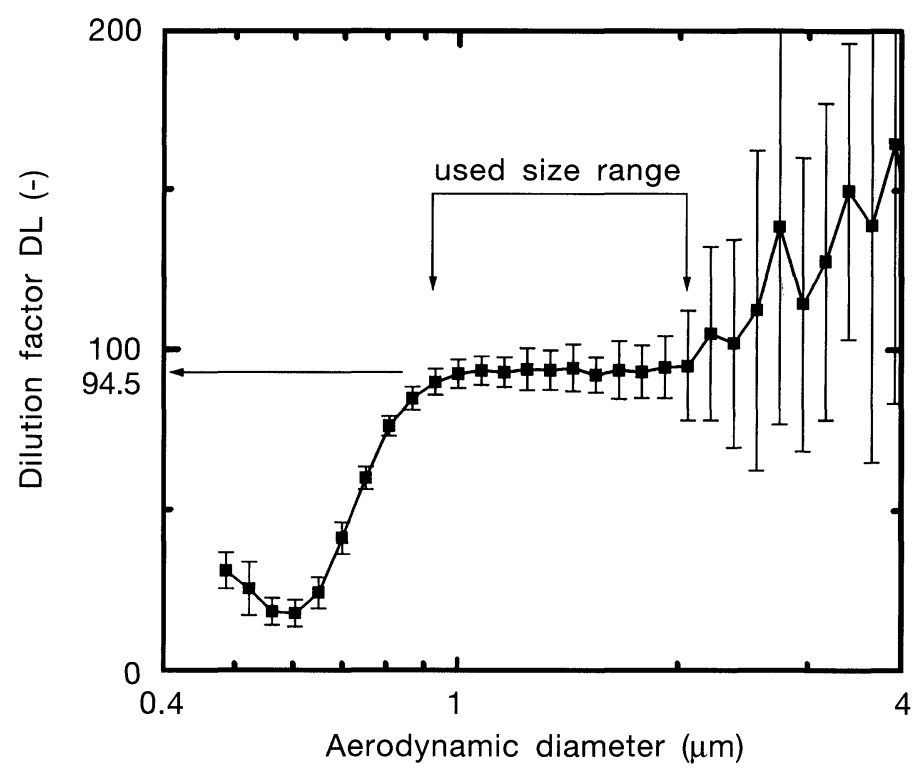

Fig. 3. Relationship between aerodynamic diameter of quartz particles and dilution factor $D L$. $\left(D L=C_{2} / C_{1}\right.$ without filter $)$

penetration of filters depends on the diameter of the aerosol particles. Error bars in the figure refer to the standard deviations of the eight test samples. Filter \#1 and filter \#2 in Figure 4 are typical examples among the ten types of filters, and both are made by the same manufacturer. Penetration largely depends on the type and brand of filters. The measured penetration curves for other filters showed different dependencies on particle diameter.

The results using neutralized dust show higher penetrations than when no neutralizer was used. This suggests that filter performance may be overestimated if electrostatic charge is not considered for the test aerosol.

The present standards of dust respirators do not account for electrostatic charge of test aerosol and the testing procedures are performed without the use of neutralizer. Powder dispersion in the air by the dust feeder induces electrostatic charges on the particles. The weak radioisotope used in this study may not emit enough a ray to achieve the equilibrium charge distribution due to the high concentration and the high flow rate of the test aerosol passing through the neutralizer. Further quantitative measurements are needed to clarify the relationship between electric charges on the particles and filtration efficiency.

Figure 5 shows the relationship between aerodynamic diameter and penetration of quartz dust. Filtration efficiency obtained from photometers are also shown in the figure. From the figure, the equivalent diameter is $1.0 \mu \mathrm{m}$ for filter \#1 and $1.1 \mu \mathrm{m}$ for filter \#2. This equivalent diameter is related to the sensitivity of the 


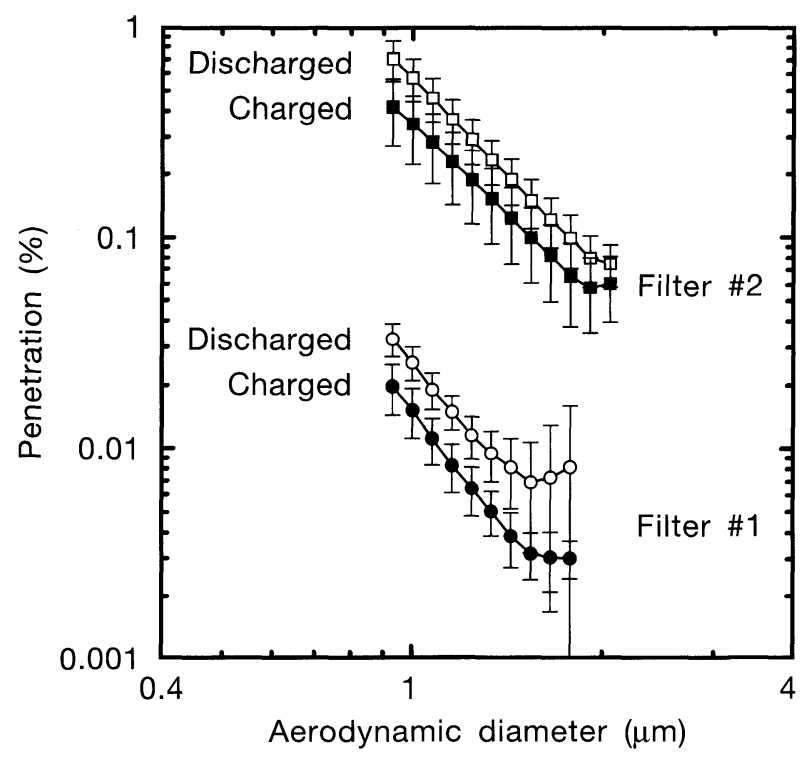

Fig. 4. Relationship between aerodynamic diameter and penetration of two test filters. The figure shows cases of normal test aerosol and aerosol discharged by ${ }^{241} \mathrm{Am}$.

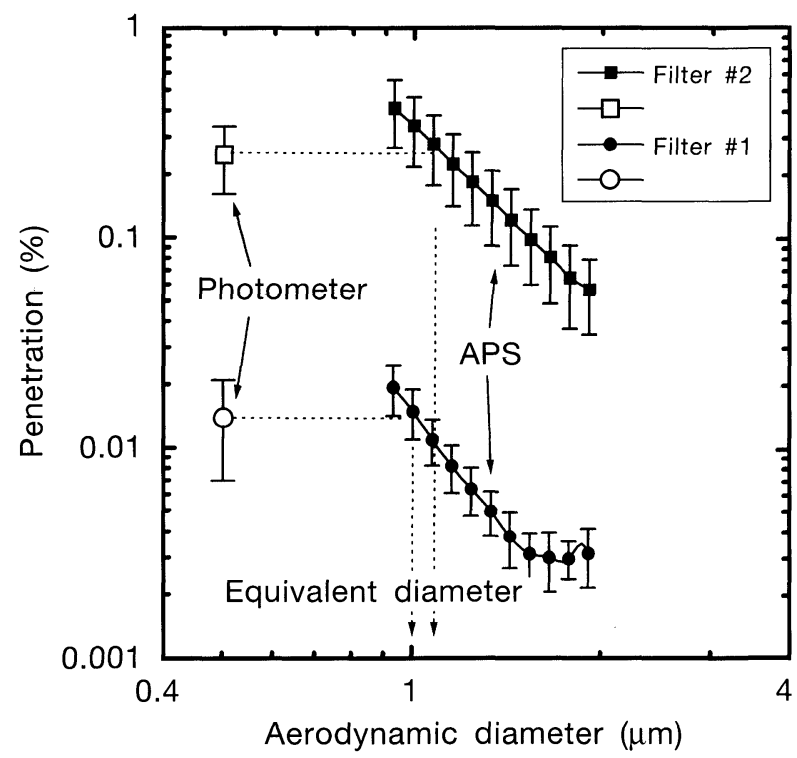

Fig. 5. The penetration of test filters as measured by APS-33B and light scattering photometers (AP634). Penetration by the photometers shows no information about particle diameter. The equivalent diameter is defined as the aerodynamic diameter measured by APS-33B, which shows the same penetration through the test filter as that measured by the photometer. 
light scattering photometer, the penetration curve relationship to size, and the size distribution of the test aerosols.

In Figure 6, equivalent diameters indicated different values for the ten types of filters, with and without neutralizer as shown. Some test filters attract dust by electrostatic force, while others collect dust only by inertia and diffusion effects. All equivalent diameters for the test filters were around $1 \mu \mathrm{m}$ irrespective of neutralization of the test aerosol. The variance of the equivalent diameters in Figure 6 are attributable to the different dust collection mechanisms of each filter.

\section{Conclusion}

This study indicates that the size of the quartz particles used in the current national approval test for dust respirators is equivalent to about $1 \mu \mathrm{m}$ of aerodynamic diameter. Recently, the high performance masks to remove submicron particles, for example welding fume, were demanded at many workplaces. In addition, the use of charged quartz dust may cause misunderstandings regarding the filter performance. Improvements in the testing methods prescribed in the present standards of dust respirators will be required in future. Equivalent diameter data for test aerosols will be useful to make comparisons between the filtration performance as measured by present test aerosol and when using alternative submicron test aerosols.

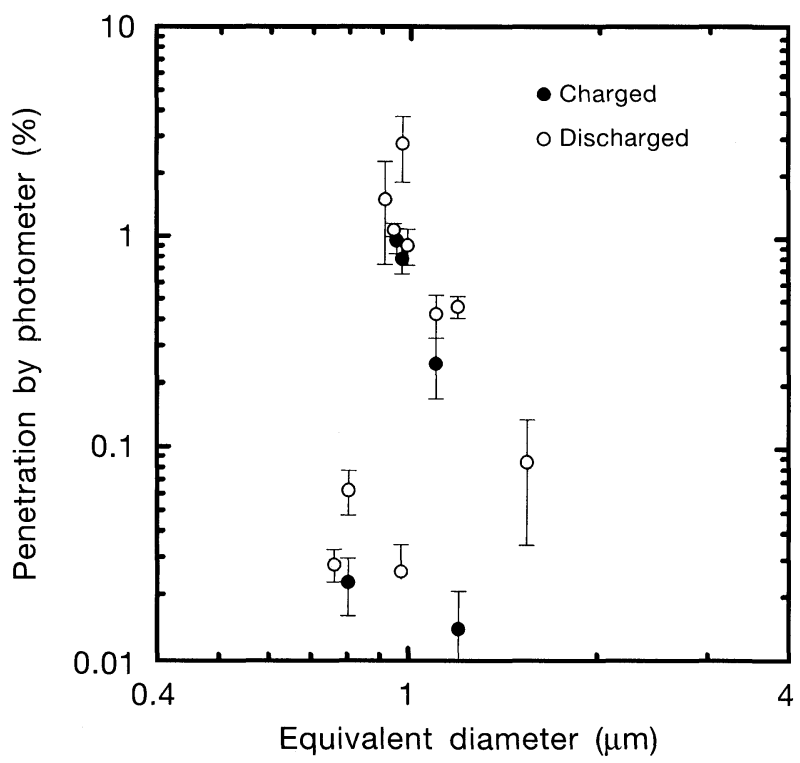

Fig. 6. Equivalent diameters of dust respirators. Penetration was measured by the light scattering photometer. 


\section{ACKNOWLEDGMENTS}

The authors thank Mr. Takuro Sohma, Ms. Kanna Matsuura, and Mr. Makoto Shindo for their assistance.

\section{REFERENCES}

1) Standards for dust respirators. The Ministry of Labour Japan, Notification No. 191988.

2) Koshi S. Studies on the high efficiency dust respirator. Bull Nat Inst Ind Health 1960; 3: 2339.

3) Soda R. An investigation of molecular structure of the polymer synthesized from p-tert-butylphenol and formaline with ammonia by means of an infrared spectroscopy. Bull Nat Inst Ind Health 1960; 3: 40-55.

4) Koshi S. On the characteristics of the digital dust indicator. Ind Health 1960; 2: 189-207.

5) Homma K. Measuring method for mass concentration of suspended particulate matter. Kankyou Jouhou Kagaku 1978; 7: 30-7 (in Japanese).

6) Johnston AM, Vincent JH, Jones AD. Electrical charge characteristics of dry aerosols produced by a number of laboratory mechanical dispensers. Aerosol Sci Tech 1987; 6: 115-27.

7) Leakage rate testing method for facepieces of respirators. Japanese Industrial Standard JIS T81591983.

8) Dust respirators for fine particles. Japanese Industrial Standard JIS T-8160 1993.

9) Respiratory protective devices-Particle filters-Requirements, testing, marking. European Standard EN 1431990.

10) Respiratory protective devices. Code of Federal Regulations Title 42 Part 84, Public Health Service, U.S.A. 1995.

11) Remiarz RJ, Agarwal JK, Quant FR, Sem GJ. Real-time aerodynamic particle size analyzer. The Proceedings of the International Symposium on Aerosols in the Mining and Industrial Work Environment. Minneapolis: Ann Arbor Science, Michigan 1983; 3: 879-95.

12) Chen CC, Willeke K. Aerosol penetration through surgical masks. Am J Infect Cont 1992; 20: $177-84$.

13) Chen CC, Ruuskanen J, Pilacinski W, Willeke K. Filter and leak penetration characteristics of a dust and mist filtering facepiece. Am Ind Hyg Assoc J 1990; 51: 632-9. 